ARTICLE

https://doi.org/10.1038/s41467-020-15925-2

\title{
Voltage- and time-dependent valence state transition in cobalt oxide catalysts during the oxygen evolution reaction
}

Jing Zhou ${ }^{1}$, Linjuan Zhang $\mathbb{D}^{1,2}{ }^{\infty}$, Yu-Cheng Huang ${ }^{3}$, Chung-Li Dong ${ }^{3}$, Hong-Ji Lin ${ }^{4}$, Chien-Te Chen ${ }^{4}$, L. H. Tjeng (iD ${ }^{5} \&$ Zhiwei Hu (iD ${ }^{5 凶}$

The ability to determine the electronic structure of catalysts during electrochemical reactions is highly important for identification of the active sites and the reaction mechanism. Here we successfully applied soft $\mathrm{X}$-ray spectroscopy to follow in operando the valence and spin state of the $\mathrm{Co}$ ions in $\mathrm{Li}_{2} \mathrm{Co}_{2} \mathrm{O}_{4}$ under oxygen evolution reaction (OER) conditions. We have observed that a substantial fraction of the $\mathrm{Co}$ ions undergo a voltage-dependent and timedependent valence state transition from $\mathrm{Co}^{3+}$ to $\mathrm{Co}^{4+}$ accompanied by spontaneous delithiation, whereas the edge-shared $\mathrm{Co}-\mathrm{O}$ network and spin state of the $\mathrm{Co}$ ions remain unchanged. Density functional theory calculations indicate that the highly oxidized $\mathrm{Co}^{4+}$ site, rather than the $\mathrm{Co}^{3+}$ site or the oxygen vacancy site, is mainly responsible for the high OER activity.

\footnotetext{
${ }^{1}$ Key Laboratory of Interfacial Physics and Technology, Shanghai Institute of Applied Physics, Chinese Academy of Sciences, Shanghai 201800 , China. 2 University of Chinese Academy of Sciences, Beijing 100049, China. ${ }^{3}$ Department of Physics, Tamkang University, 151 Yingzhuan Road, New Taipei City 25137, Taiwan. ${ }^{4}$ National Synchrotron Radiation Research Center, 101 Hsin-Ann Road, Hsinchu 30076, Taiwan. ${ }^{5}$ Max Planck Institute for Chemical Physics of Solids, Nöthnitzer Strasse 40, 01187 Dresden, Germany. ${ }^{凶}$ email: zhanglinjuan@sinap.ac.cn; zhiwei.hu@cpfs.mpg.de
} 
T he oxygen evolution reaction (OER) plays a crucial role in many modern energy storage and conversion technologies such as solar/electricity-driven water splitting systems, rechargeable metal-air batteries, and regenerative fuel cells. However, the OER still constitutes a bottleneck in these electrochemical devices because of the intrinsically sluggish kinetics involving multistep proton-coupled electron transfer processes ${ }^{1,2}$. The widespread use of alkaline water electrolysis for the OER strongly depends on the availability of low-cost and efficient electrocatalysts. New materials need to be designed to replace the benchmark OER catalysts that typically consist of precious metal oxides such as $\mathrm{IrO}_{2}$ and $\mathrm{RuO}_{2}$. For this purpose, $3 d$ transitionmetal (TM) oxides have recently emerged as promising candidates. They are inexpensive because they are earth abundant and environmentally friendly and have tunable chemical reactivities depending on the type of electronic and crystal structures. During the past decade, many $3 d$ oxides such as spinels ${ }^{3,4}$, perovskites ${ }^{5,6}$, rock salt ${ }^{7}$, and oxyhydroxides ${ }^{8-12}$, have become serious candidates for OER catalysts. The intricate interplay of charge, spin, orbital, and coordination degrees of freedom of $3 d$ ions in oxides makes possible the preparation of highly active catalysts ${ }^{5,6,13}$.

The theoretical description of the OER involves four electron charge-transfer steps on surface metal sites. Very recently, anionic redox processes at lattice-oxygen sites were also considered ${ }^{14,15}$. These are complex processes, and tremendous efforts have been devoted to identifying the key parameters $5,6,12,13,16$. These parameters are usually identified based on the electronic structure of the as-prepared materials. There is, however, an increasing amount of evidence that electrocatalysts also undergo crystallographic changes under OER conditions ${ }^{8,17-19}$. For example, surface amorphization combined with a change in the $\mathrm{Co}-\mathrm{O}$ network from corner-sharing to edge-sharing was observed for $\mathrm{Ba}_{0.5} \mathrm{Sr}_{0.5} \mathrm{Co}_{0.8} \mathrm{Fe}_{0.2} \mathrm{O}_{3-\delta}$ (Ref. ${ }^{20}$ ). Under an electric field, $\mathrm{SrCoO}_{3-\delta}$ converts from the perovskite phase to brownmillerite $\mathrm{SrCoO}_{2.5}$ and further to the unexplored $\mathrm{H}-\mathrm{SrCoO}_{2.5}$ phase ${ }^{21,22}$.

It is clear that in operando experimental studies are needed to elucidate the mechanism of the OER. Many particular intermediate states of $3 d$ TM-oxide catalysts were identified by previous operando infrared spectroscopic studies ${ }^{23-26}$. The earlier infrared work identified the oxyl radical (Ti-O*) at the $\mathrm{n}-\mathrm{SrTiO}_{3} /$ aqueous interface ${ }^{24}$, while very recent work indicated both the oxyl radical ( $\left.\mathrm{Ti}-\mathrm{O}^{*}\right)$ that terminates the surface, and the bridged intermediate ( $\left.\mathrm{Ti}-\mathrm{O}^{-}-\mathrm{Ti}\right)$ parallel to the surface ${ }^{26}$. Other operando infrared spectroscopic studies also observed the $\mathrm{Co}(\mathrm{IV})=\mathrm{O}$ intermediate in $\mathrm{Co}_{3} \mathrm{O}_{4}$ with a mixed $\mathrm{Co}^{2+} / \mathrm{Co}^{3+}$ valence state ${ }^{23}$, and the $\mathrm{Fe}(\mathrm{IV})=\mathrm{O}$ intermediate in haematite $\left(\alpha-\mathrm{Fe}_{2} \mathrm{O}_{3}\right)$ with an $\mathrm{Fe}^{3+}$ state $^{25}$. The objective should not only be to follow the crystal structure changes, but also to record and understand the electronic structure and its modifications during the reaction. In fact, depending on how detailed and specific the information is, knowledge about the electronic structure can be most valuable for identification of the active sites. The soft X-ray absorption spectra at the $3 d \mathrm{TM}-\mathrm{L}_{2,3}$ and $\mathrm{O}-\mathrm{K}$ edges are highly sensitive to the valence state, spin state, and local environment of $3 d$ TM elements. Note that the valence-state transition of a high-valent TM element does not necessarily indicate a gain of one hole in the metal $3 d$ state. For instance, the $\mathrm{Co}^{4+}$ oxides $\mathrm{BaCoO}_{3}$ (Ref. ${ }^{27}$ ) and $\mathrm{SrCoO}_{3}$ (Ref. ${ }^{28}$ ) are negative charge-transfer systems, in which the $3 d^{5}$ configuration has a contribution of $<10 \%$, whereas the dominant configuration is $3 d^{6} \mathrm{~L}$ ( $\mathrm{L}$ stands for the hole in the ligand $\mathrm{O} 2 p$ states) with $t_{2 g}{ }^{5} e_{g} \underline{L}_{e g}$ for a low-spin state and $t_{2 g}{ }^{4} e_{g}{ }^{2} \underline{\mathrm{L}}_{e g}$ for an intermediate-spin state as shown in Ref. ${ }^{28}$, induced by very strong covalence between Co $3 d$ and O $2 p$. Such $\mathrm{O} 2 p$ holes can be directly studied by soft X-ray absorption spectroscopy (SXAS) at the O-K edge, especially for an edgeshared $\mathrm{Co}-\mathrm{O}$ network, which presents a well-separated $\mathrm{Co}^{3+}$. and $\mathrm{Co}^{4+}$-related spectral feature in the spectra of $\mathrm{Co}^{3+} / \mathrm{Co}^{4+}$ mixed valence oxides ${ }^{29,30}$. Thus, the O-K SXAS spectra can generally be used to explore the $\mathrm{Co}^{4+}$ content via Co $3 \mathrm{~d}-\mathrm{O} 2 p$ covalence ${ }^{27,28}$.

Here we apply SXAS at the Co- $\mathrm{L}_{2,3}$ and $\mathrm{O}-\mathrm{K}$ edges to determine in operando the valence state, spin state, and local coordination of the $\mathrm{Co}$ ions in $\mathrm{Li}_{2} \mathrm{Co}_{2} \mathrm{O}_{4}$ during the OER. $\mathrm{Li}_{2} \mathrm{Co}_{2} \mathrm{O}_{4}$ has the best OER activity among materials with spinel structures and is quite comparable to the well-known benchmark $\mathrm{IrO}_{2}{ }^{31}$. The very detailed information that we were able to obtain about the Co local electronic structure allowed us to deduce that under OER conditions a substantial fraction of the $\mathrm{Co}^{3+}$ ions was converted into high-valent $\mathrm{Co}^{4+}$. This is associated with a delithiation process that also took place. Importantly, after the OER, the lowspin state of the Co ions and the edge-shared $\mathrm{Co}-\mathrm{O}$ network remain unchanged. By combining these results with those obtained by density functional theory calculations, we can then infer that the $\mathrm{Co}^{4+}$ sites (with a dominant oxygen ligand hole ground state) are responsible for the high OER activity. Although it is experimentally challenging to separate the electrochemical liquid cell from the ultrahigh vacuum, our study shows that SXAS in operando is the spectroscopic method of choice for the investigation of TM $3 d$-based catalysts since the atomic-like multiplet structures in the spectra contain highly specific information about the valence, spin, and local coordination of the $3 d$ ions.

\section{Results}

pH-dependence of the OER activity. We started by studying the $\mathrm{pH}$-dependence of the OER activity, which can provide us with an initial overview of the possible active sites and reaction paths ${ }^{14,32,33}$. It was suggested that a conventional OER involving four concerted proton-electron transfer steps on a surface metalion center, exhibited $\mathrm{pH}$-independent activity, while latticeoxygen oxidation from highly covalent oxides involving nonconcerted proton-electron transfer steps exhibited a strong $\mathrm{pH}$ dependent OER activity ${ }^{14}$. The strong $\mathrm{pH}$-independent activity of Ni-based OER catalysts was attributed to the formation of negatively charged surface sites that act as OER precursors originating from a deprotonation ${ }^{32}$ or was associated with severe surface degradation in addition to the redox activity of lattice oxygen ${ }^{33}$. In the spinel oxide $\mathrm{ZnFe}_{0.4} \mathrm{Co}_{1.6} \mathrm{O}_{4}$, the $\mathrm{pH}$-dependent OER activity was assigned as decoupled proton-electron transfers, while the lattice-oxygen contribution was excluded, considering the wide energy gap between the $\mathrm{O}$ p-band center and the Fermi level due to the cation-deficient spinel ${ }^{34}$. Figure 1a presents the OER performance of $\mathrm{Li}_{2} \mathrm{Co}_{2} \mathrm{O}_{4}$. It is apparent that the OER activity of $\mathrm{Li}_{2} \mathrm{Co}_{2} \mathrm{O}_{4}$ has a strong pH-dependence, very similar to that of $\mathrm{ZnFe}_{0.4} \mathrm{Co}_{1.6} \mathrm{O}_{4}$ having a $\mathrm{Co}^{3.34+}$ valence state but very different from that of $\mathrm{LaCoO}_{3}$, which contains pure $\mathrm{Co}^{3+}$. This is the first indication that the Co valence of $\mathrm{Li}_{2} \mathrm{Co}_{2} \mathrm{O}_{4}$ may have changed during the OER. We note that surface degradation as the origin of the $\mathrm{pH}$-dependent OER activity can be excluded. Supplementary Fig. 1 shows, for example, that the $\mathrm{Li}_{2} \mathrm{Co}_{2} \mathrm{O}_{4}$ catalyst has excellent electrochemical stability, as indicated by the nearly constant overpotential over $100 \mathrm{~h}$.

Our next step was to investigate the electronic structure of $\mathrm{Li}_{2} \mathrm{Co}_{2} \mathrm{O}_{4}$ as a function of applied voltage and time, and for this we analyzed the cyclic voltammograms to select the voltages for the SXAS experiments. Figure $1 \mathrm{~b}$ shows the cyclic voltammograms recorded at a scan rate of $5 \mathrm{mV} \mathrm{s}^{-1}$ with $\mathrm{Li}_{2} \mathrm{Co}_{2} \mathrm{O}_{4}$ loading on carbon paper. We observed two redox transitions in the cyclic voltammogram: a weak transition at $1.25 \mathrm{~V}$ (vs. reversible hydrogen electrode (RHE)) and a relatively strong peak at $1.40 \mathrm{~V}$. In $\mathrm{CoO}, \mathrm{Co}_{3} \mathrm{O}_{4}$, and $\mathrm{CoOOH}$, two transitions at 1.4 and $1.5 \mathrm{~V}$ 

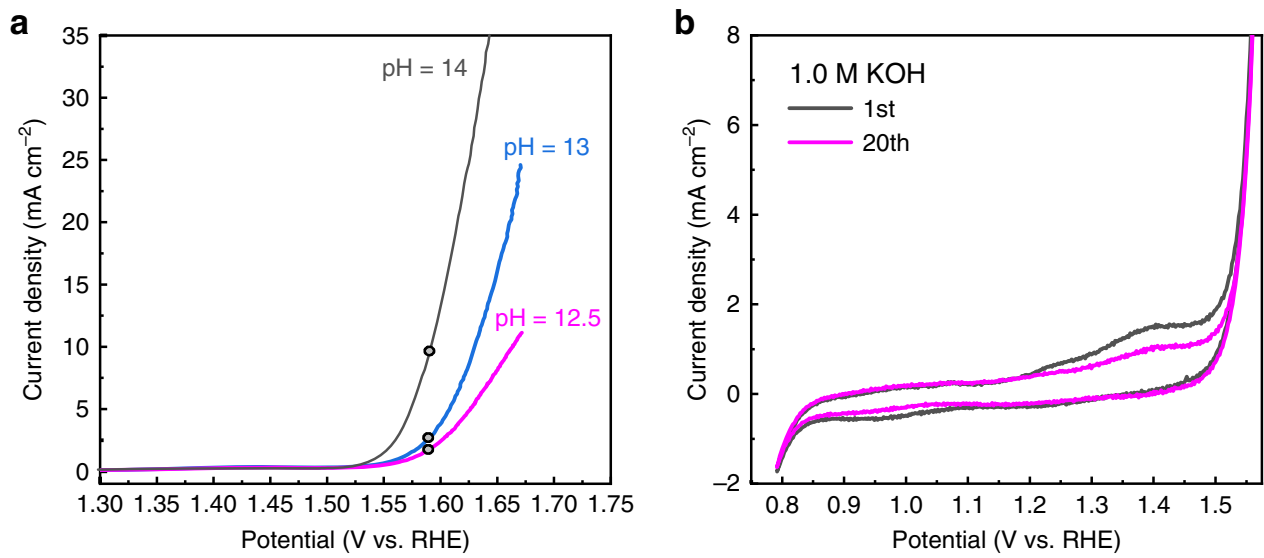

Fig. 1 OER activity of $\mathrm{Li}_{2} \mathrm{Co}_{\mathbf{2}} \mathbf{O}_{\mathbf{4}}$. a Polarization curves for $\mathrm{Li}_{2} \mathrm{Co}_{2} \mathrm{O}_{4}$ in $\mathrm{O}_{2}$-saturated $\mathrm{KOH}(\mathrm{pH}=12.5-14)$ at a scan rate of $10 \mathrm{mV} \mathrm{s}$. . b Cyclic voltammograms of $\mathrm{Li}_{2} \mathrm{CO}_{2} \mathrm{O}_{4}$ loading on carbon paper at a scan rate of $5 \mathrm{mV} \mathrm{s}^{-1}$ for the 1st cycle (black) and the 20th cycle (magenta).

were previously attributed to the $\mathrm{Co}^{2+} / \mathrm{Co}^{3+}$ and $\mathrm{Co}^{3+} / \mathrm{Co}^{4+}$ redox couples, respectively ${ }^{4}$. Since we have only a $\mathrm{Co}^{3+} / \mathrm{Co}^{4+}$ redox couple, the relatively strong peak at $1.4 \mathrm{~V}$ might correspond a sharp valence-state transition of cobalt ions from $\mathrm{Co}^{3+}$ to $\mathrm{Co}^{4+}$, while the weak feature at $1.25 \mathrm{~V}$ was assigned to a minor contribution from the of $\mathrm{Co}^{3+} \rightarrow \mathrm{Co}^{4+}$ transition, as shown in Fig. $1 \mathrm{~b}$. The height of the strong peak at $1.4 \mathrm{~V}$ decreases with an increasing number of CV scans from the 1st cycle (black) to the 20th cycle (magenta). This might suggest that the number of cobalt ions expected to undergo the valence-state transition gradually decreases in $\mathrm{Li}_{2} \mathrm{Co}_{2} \mathrm{O}_{4}$. Here, we observed a sharp increase in the current density at $1.55 \mathrm{~V}$, where the material is activated to be a stable, highly active OER catalyst under electrochemical conditions.

In operando SXAS studies under OER conditions. In Fig. 2a, b we present the $\mathrm{O}-\mathrm{K}$ spectra of $\mathrm{Li}_{2} \mathrm{Co}_{2} \mathrm{O}_{4}$ in operando as a function of the number of scans (taken within 2 min for each scan) and the applied voltages. Upon applying $1.4 \mathrm{~V}$, the current density is still very weak, as shown in Fig. 1b. However, one can already observe in Fig. 2a a clear increase in the intensity of two new spectral features, $\beta$ and $\gamma$, with an increasing number of scans. After 10 scans (20 min), the spectral intensities of $\beta$ and $\gamma$ reach a maximum and remain unchanged with further scans as shown in Supplementary Fig. 2. For an applied voltage of $1.6 \mathrm{~V}$, under which there is a sharp rise in the current density, as displayed in Fig. 1b, the spectral intensities of peaks $\beta$ and $\gamma$ increase much more quickly, as shown in Fig. 2b. The intensity increase stopped after 20 min (see Supplementary Fig. 2) but reached a much higher maximum value.

To interpret the time-dependent O-K SXAS spectra taken at 1.4 and $1.6 \mathrm{~V}$, we also present for comparison in Fig. $2 \mathrm{c}$ the spectra of the layered $\mathrm{LiCoO}_{2}$ (cyan line), $\mathrm{Li}_{0.66} \mathrm{CoO}_{2}$ (orange line, from Ref. ${ }^{29}$ ), and the layered $\mathrm{Na}_{0.5} \mathrm{CoO}_{2}$ (dark cyan line, from Ref. ${ }^{30}$ ) having $\mathrm{Co}^{3+}, \mathrm{Co}^{3.34+}$, and $\mathrm{Co}^{3.5+}$ valence states, respectively. All three reference materials have the same lowspin state and the same edge-shared $\mathrm{Co}-\mathrm{O}$ network at a $90^{\circ}$ $\mathrm{Co}-\mathrm{O}-\mathrm{Co}$ bond angle. The absolute energy positions of all spectra were calibrated using the sharp pre-edge peak at $531.7 \mathrm{eV}$ in the O-K SXAS spectrum of $\mathrm{NiO}$ measured simultaneously ${ }^{35}$. All the peaks below $533 \mathrm{eV}$ represent the unoccupied $\mathrm{O} 2 p$ states that are mixed into the unoccupied Co $3 d$ states. The sharp single peak $\alpha$ at $530.25 \mathrm{eV}$ for the as-prepared $\mathrm{Li}_{2} \mathrm{Co}_{2} \mathrm{O}_{4}$ in Fig. $2 \mathrm{a}$, b, as well as that for $\mathrm{LiCoO}_{2}$ in Fig. $2 c$, reflects a fully occupied $t_{2 g}{ }^{6}$ state associated with the low-spin $\mathrm{Co}^{3+}$ ion $^{29}$. In this case, only transitions to the unoccupied $e_{g}$ states are possible. For the mixed-valent Co oxides $\mathrm{Li}_{0.66} \mathrm{CoO}_{2}$ (from Ref. ${ }^{29}$ ) and $\mathrm{Na}_{0.5} \mathrm{CoO}_{2}$ (from Ref. ${ }^{30}$ ), two additional peaks, $\beta$ and $\gamma$, appear at lower energies. They originate from transitions to the unoccupied $t_{2 g}$ and $e_{g}$ orbitals of the $\mathrm{Co}^{4+}$ ion, respectively, as also observed in $\mathrm{BaCoO}_{3}$ (see Fig. 2e, $\mathrm{f}$ (blue line)), also having the low-spin state and the same $90^{\circ} \mathrm{Co}-\mathrm{O}-\mathrm{Co}$ bond angle. Thus, the increase in the spectral intensities of the $\beta$ and $\gamma$ features during the OER indicates an increase in the Co valence state. In other words, there is a transition from a $\mathrm{Co}^{3+}$ state to a $\mathrm{Co}^{4+}$ state in part of the $\mathrm{Li}_{2} \mathrm{Co}_{2} \mathrm{O}_{4}$ catalyst during the electrochemical reaction. The spectra of $\mathrm{Li}_{2} \mathrm{Co}_{2} \mathrm{O}_{4}$ at different applied voltages are presented in Fig. 2d, where one can observe only a negligible amount of $\mathrm{Co}^{4+}$ ions at $1.2 \mathrm{~V}$. The spectral intensity of $\mathrm{Co}^{4+}(\beta$ and $\gamma)$ in $\mathrm{Li}_{2} \mathrm{Co}_{2} \mathrm{O}_{4}$ after 20 min under an applied voltage of $1.4 \mathrm{~V}$ is only slightly smaller than that of $\mathrm{Na}_{0.75} \mathrm{CoO}_{2}$ in the $\mathrm{Co}^{3.25}$ state ${ }^{30}$, while after 20 min under $1.6 \mathrm{~V}$, it lies between those of $\mathrm{Li}_{0.66} \mathrm{CoO}_{2}$ and $\mathrm{Na}_{0.5} \mathrm{CoO}_{2}$. The $\mathrm{Co}$ valence in these two cases can be estimated by constructing a weighted sum of the $\mathrm{Li}_{2} \mathrm{Co}_{2} \mathrm{O}_{4}$ spectrum (blue line) and $\mathrm{BaCoO}_{3}$ spectrum (cyan line, from Ref. ${ }^{27}$ ), as shown in Fig. 2e, f. We find $\mathrm{Co}^{3.2+}$ and $\mathrm{Co}^{3.4+}$ valences for these two cases, respectively.

Using the same procedure as shown in Fig. 2e, f, we extract and display in Fig. 3a the time evolution of the Co valence under applied voltages of 1.4 (black open squares) and $1.6 \mathrm{~V}$ (magenta open circles). In Fig. $3 \mathrm{~b}$ and Supplementary Table 1, we show the lithium content as a function of time. The data sets reveal that the composition of the as-prepared material, i.e., at $0 \mathrm{~min}$ in Fig. 3b, is in accordance with the chemical formula of $\mathrm{Li}_{2} \mathrm{Co}_{2} \mathrm{O}_{4}$, and after $20 \mathrm{~min}$ of the OER at an applied voltage of $1.6 \mathrm{~V}$, half of the lithium ions were removed. The current density $j$ (solid line), as shown in Fig. 3c, also has a similar trend with time. This strongly indicates that the OER activity is directly related to the appearance of $\mathrm{Co}^{4+}$ ions.

We have carried out a number of verification experiments to ensure that our experimental observations are correct. We also carried out O-K SXAS measurements under ultrahigh vacuum conditions. In Fig. $2 \mathrm{c}$ we show the in vacuo spectrum of $\mathrm{Li}_{2} \mathrm{Co}_{2} \mathrm{O}_{4}$ after $20 \mathrm{~min}$ of OER under an applied voltage of $1.6 \mathrm{~V}$ (magenta circles). A comparison with the in operando spectrum (black circles) reveals that the spectra are identical in the energy region of interest. There are differences between the in vacuo and in operando spectra, but these occur only in the energy region above $533 \mathrm{eV}$. As illustrated in Supplementary Fig. 3, there is extra background in the in operando spectrum above $533 \mathrm{eV}$, which can be attributed to the oxygen in the electrolyte. Thus, from the relevant features that appear below $533 \mathrm{eV}$, we can safely conclude that the O-K SXAS experiments (in operando and in vacuo) establish the irreversible valence change of Co during the 

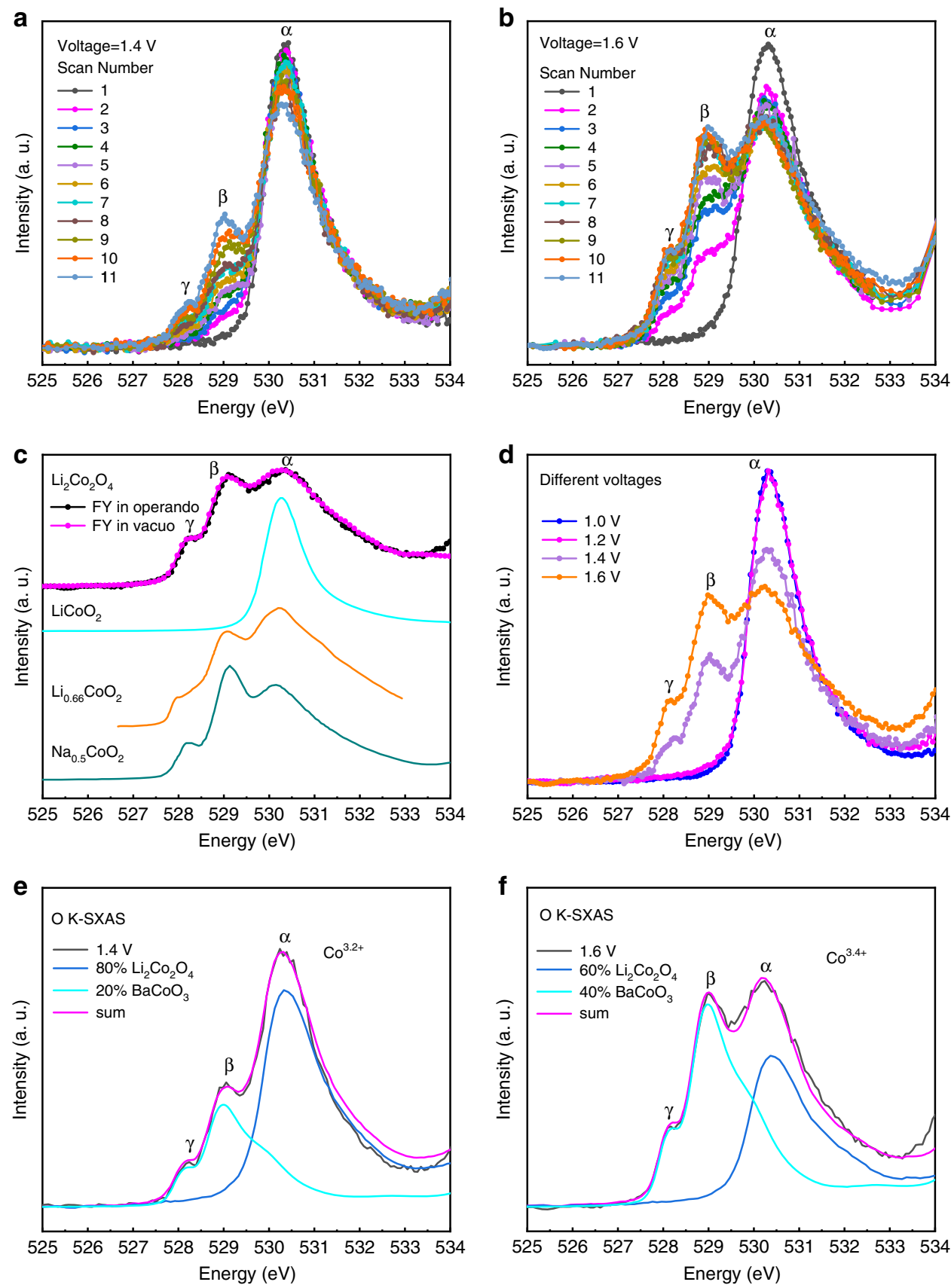

Fig. 2 In operando O-K SXAS spectra of $\mathrm{Li}_{\mathbf{2}} \mathrm{CO}_{\mathbf{2}} \mathbf{O}_{\mathbf{4}} \cdot \mathbf{a}, \mathbf{b}$ O-K SXAS spectra of $\mathrm{Li}_{2} \mathrm{CO}_{2} \mathrm{O}_{4}$ in operando as a function of the number of scans (2 min for each scan) at applied voltages of 1.4 and $1.6 \mathrm{~V}$, respectively. c Comparison of the spectra during the OER (black circles, in operando) and after the OER (magenta circles, in vacuo). Also included are the spectra of $\mathrm{LiCoO}_{2}$ (cyan line) with the low-spin $\mathrm{Co}^{3+}$ state, mixed-valent $\mathrm{Co}_{0}$ oxide $\mathrm{Li}_{0.66} \mathrm{CoO}_{2}($ orange line, from Ref. ${ }^{29}$ ), and $\mathrm{Na}_{0.5} \mathrm{CoO}_{2}$ (dark cyan line, from Ref. ${ }^{30}$ ) with the same $90^{\circ} \mathrm{Co}-\mathrm{O}-\mathrm{Co}$ bond angle. $\mathbf{d}$ Spectra of $\mathrm{Li}_{2} \mathrm{Co}_{2} \mathrm{O}_{4}$ at different applied voltages.

e, $\mathbf{f}$ Experimental (black lines) and simulated (magenta lines) spectra of $\mathrm{Li}_{2} \mathrm{Co}_{2} \mathrm{O}_{4}$ under an applied voltage of 1.4 and $1.6 \mathrm{~V}$, respectively, with the simulations being constructed as weighted sums of the spectra of the as-prepared $\mathrm{Li}_{2} \mathrm{Co}_{2} \mathrm{O}_{4}$ (blue) representing the low-spin $\mathrm{Co}^{3+}$ state and of $\mathrm{BaCoO}_{3}$ (cyan, from Ref. ${ }^{27}$ ) representing the low-spin $\mathrm{Co}^{4+}$ configuration.

electrochemical reaction. Next, we also performed SXAS experiments at the Co- $\mathrm{L}_{2,3}$ edges. In Supplementary Fig. 4e, we show that there is a change and shift to higher energies of the Co spectrum when comparing the $\mathrm{Li}_{2} \mathrm{Co}_{2} \mathrm{O}_{4}$ after the OER with the as-prepared $\mathrm{Li}_{2} \mathrm{Co}_{2} \mathrm{O}_{4}$, indicating an increase in the $\mathrm{Co}$ valence ${ }^{27,36,37}$. We also quantitatively analyzed the Co- $\mathrm{L}_{2,3}$ spectra in terms of a weighted superposition of the theoretical LS $\mathrm{Co}^{3+}$ and $\mathrm{LS} \mathrm{Co}^{4+}$ spectra, see Supplementary Fig. 5a. We found $60 \% \mathrm{Co}^{3+}$ and $40 \% \mathrm{Co}^{4+}$, i.e., an $\mathrm{LS} \mathrm{Co}^{3.4+}$ state, which is fully consistent with the O-K data. We note that the sharp low- energy shoulder $\mathrm{S}$ at $779.7 \mathrm{eV}$ in the $\mathrm{Co}-\mathrm{L}_{2,3}$ spectra as displayed in Supplementary Figs. 4e and 5a is a transition to the unoccupied $t_{2 g}$ and a fingerprint of the $\mathrm{LS} \mathrm{Co}^{4+}$ state, as observed in the $\mathrm{BaCoO}_{3}$ spectrum (wine) in Supplementary Fig. 4a. As a final check, we also measured the $\mathrm{Co}-\mathrm{L}_{2,3}$ and $\mathrm{O}-\mathrm{K}$ spectra by the more surface-sensitive total electron yield (TEY) method for comparison with the total fluorescence yield (TFY) spectra. Supplementary Fig. 5a, b reveals that the Co- $\mathrm{L}_{2,3}$ spectra are very similar and thus also extracted the Co valence, i.e., $\mathrm{Co}^{3.35+}$ in TEY versus $\mathrm{Co}^{3.4+}$ in TFY. Supplementary Fig. $6 \mathrm{~b}$, c shows that 


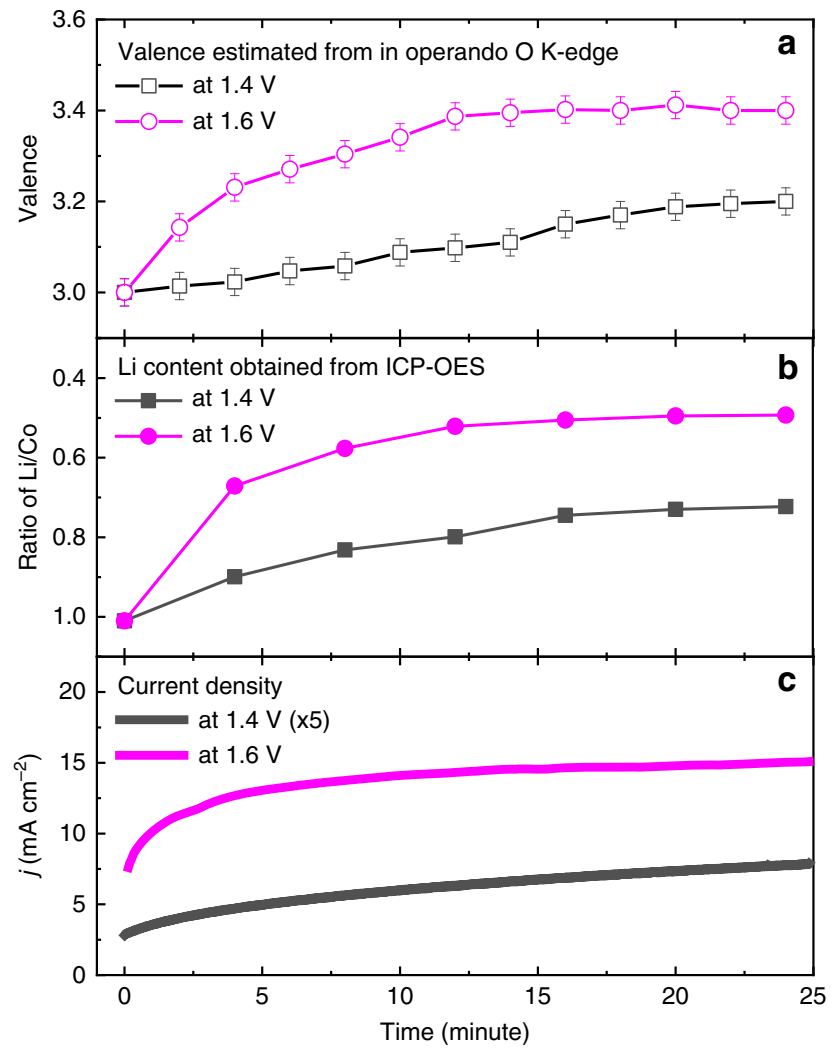

Fig. 3 Evolution of $\mathrm{Li}_{2} \mathrm{CO}_{2} \mathrm{O}_{4}$ under applied voltages of 1.4 and $1.6 \mathrm{~V}$ over time. a Change in the Co valence determined from in operando SXAS, $\mathbf{b}$ evolution of the lithium/cobalt ratio, c evolution of current density $j$.

the relative spectral weight of the $\beta$ and $\gamma$ features in the $\mathrm{O}-\mathrm{K}$ SXAS is also only slightly smaller in the TEY than in the TFY, fully consistent with the Co- $\mathrm{L}_{2,3}$ findings. We note that these small differences between the TEY and TFY spectra may suggest that part of the $\mathrm{Co}^{4+}$ ions at the surface are somewhat destabilized by the in vacuo conditions under which the TEY spectra were recorded. From all these checks we can safely conclude that the SXAS experiments firmly establish the irreversible change in the Co valence during the electrochemical reaction.

Structure and morphology characterization. We now investigate the effect of OER on the crystal structure of $\mathrm{Li}_{2} \mathrm{Co}_{2} \mathrm{O}_{4}$ using $\mathrm{X}$-ray powder diffraction (XRD). Figure 4a shows the data of the sample as prepared (top) and after the OER (middle) under an applied voltage of $1.6 \mathrm{~V}$ for $20 \mathrm{~min}$ in an $\mathrm{O}_{2}$-saturated $1 \mathrm{M} \mathrm{KOH}$ aqueous solution. The XRD patterns can be indexed by the standard Fd-3m symmetry (JCPDS No. 01-080-2159) corresponding to a pure spinel structure. We also observe that the patterns before and after the OER are essentially identical and that there are no additional peaks that otherwise may indicate the presence of an impurity phase. We note that there is a reflection from the carbon paper substrate, which we have indicated by the orange line at the bottom of Fig. $4 \mathrm{a}$. The results demonstrate that the overall crystalline phase of $\mathrm{Li}_{2} \mathrm{Co}_{2} \mathrm{O}_{4}$ remains unchanged after the OER. We can rule out impurity phases such as $\mathrm{Co}_{3} \mathrm{O}_{4}$, which was reported previously after the electrochemical process ${ }^{38}$. To further confirm our point, we have studied the Raman spectrum, which is also highly sensitive to impurity phases. As shown in Fig. $4 \mathrm{~b}$, the Raman spectra of $\mathrm{Li}_{2} \mathrm{Co}_{2} \mathrm{O}_{4}$ before and after the OER display four peaks at $450,487,590$, and $608 \mathrm{~cm}^{-1}$, corresponding to the $A_{1 g}+E_{g}+2 F_{2 g}$ active modes, indicating again a pure spinel structure for the sample both before and after the OER.

As a next step, we examined the atomic arrangement in the $\mathrm{Li}_{2} \mathrm{Co}_{2} \mathrm{O}_{4}$ nanoparticles in the near surface regions using a highangle annular-dark-field scanning transmission microscope (HAADF-STEM). Figure 4c, d shows the HAADF-STEM images viewed down the [110] axis of the $\mathrm{Li}_{2} \mathrm{Co}_{2} \mathrm{O}_{4}$ samples before and after the OER, respectively. We have observed that the atomic arrangement in the as-prepared nanoparticles matches very well the spinel lattice with the space group Fd-3m and that Co ions and $\mathrm{Li}$ ions occupy the $16 d$ and $16 c$ octahedral sites, respectively. The HAADF -STEM images show well-defined lattice fringes in the surface region of $\mathrm{Li}_{2} \mathrm{Co}_{2} \mathrm{O}_{4}$ samples, revealing no change in the crystal structure at the surface of $\mathrm{Li}_{2} \mathrm{Co}_{2} \mathrm{O}_{4}$ due to the OER. From the combination of SXAS, XRD, and HAADF-STEM analysis, we can infer that the low-spin state of the Co ions remains unchanged. We can also conclude that there is no complete change from the edge-shared network to corner-shared network, since the $\mathrm{O}-\mathrm{K}$ SXAS spectrum of perovskite $\left(\mathrm{La}_{1-x} \mathrm{Sr}_{x} \mathrm{CoO}_{3}\right)$ is very different from that of spinel structure $\left(\mathrm{Li}_{x} \mathrm{CoO}_{2}\right)$, as shown in Supplementary Fig. 7. The strong intersite hopping smears the difference in the spectral features in the $\mathrm{O}-\mathrm{K}$ edge between $\mathrm{Co}^{3+}$ and $\mathrm{Co}^{4+}$ for a corner-shared network in perovskite $\mathrm{La}_{1-x} \mathrm{Sr}_{\mathrm{x}} \mathrm{CoO}_{3}$, while the differences between $\mathrm{Co}^{3+}$ and $\mathrm{Co}^{4+}$ are clearly seen in the spinel structure $\mathrm{Li}_{x} \mathrm{CoO}_{2}$ (Ref. ${ }^{29}$ ) and $\mathrm{Na}_{x} \mathrm{CoO}_{2}$ (Ref. ${ }^{30}$ ) with an edge-shared network. However, we cannot exclude slight changes in the $\mathrm{Co}-\mathrm{O}-\mathrm{Co}$ bond angle. The detailed structural changes within the data presented could be revealed in the future by theoretical studies and operando XRD experiments.

DFT calculations for OER mechanisms and active sites. Having determined the valence state of the Co ions and the crystal structure under the OER condition, we now investigate the underlying mechanism and the active site for the OER performance in $\mathrm{Li}_{2} \mathrm{Co}_{2} \mathrm{O}_{4}$. For this purpose, we performed DFT calculations to model the reaction pathways. Three scenarios of the reaction mechanism were considered, as shown in Fig. 5a-c, and each involves four proton-electron transfer steps. The first one, shown in Fig. 5a, is the metal-site adsorbate evolution mechanism (MAE). This is the conventional adsorbate evolution mechanism ${ }^{12}$, which considers only the redox activity of the TM sites. The second one, shown in Fig. 5b, is the lattice-oxygen-vacancysite mechanism (LOV). This mechanism was proposed very recently ${ }^{14}$, in which the adsorbates are located at the sites of the lattice-oxygen vacancy. The last one, shown in Fig. $5 \mathrm{c}$, is the metal-and-lattice-oxygen-vacancy-site mechanism (MLOV). Here, we consider the adsorbates to be at both TM sites with different valence states and lattice-oxygen vacancy sites ${ }^{15}$. Both LOV and MLOV scenarios consider the role of the lattice-oxygen vacancies at the surface. However, the effect of the metal sites with a high oxidation state generated during the OER is explicitly taken into account in the MLOV scenario, while in the LOV scenario, the occurrence of a high oxidation state is merely considered the cause for the formation of the oxygen vacancies. We built models for $\mathrm{Li}_{2} \mathrm{Co}_{2} \mathrm{O}_{4}$ and $\mathrm{Li}_{1} \mathrm{Co}_{2} \mathrm{O}_{4}$ to reveal the effects of the occurrence of the $\mathrm{Co}^{4+}$ state generated during the OER, as shown in Supplementary Fig. 10, and calculated the free energies of the electrochemical OER process.

For $\mathrm{Li}_{2} \mathrm{Co}_{2} \mathrm{O}_{4}$, the Bader charge $(q)$ of all Co sites at the surface is +1.47 , representing $\mathrm{Co}^{3+}$ according to previous theoretical work ${ }^{12}$, while for mixed-valent $\mathrm{Li}_{1} \mathrm{Co}_{2} \mathrm{O}_{4}$, there are two different Co sites on the surface: the $\mathrm{Co}^{3+}$ site $(q=+1.49)$ and the $\mathrm{Co}^{4+}$ site $(q=+1.60)^{12}$. Figure $5 \mathrm{~d}-\mathrm{i}$ shows the free-energy diagrams under two different potentials $U(U=0$ and $1.23 \mathrm{~V}$ vs. RHE) of 

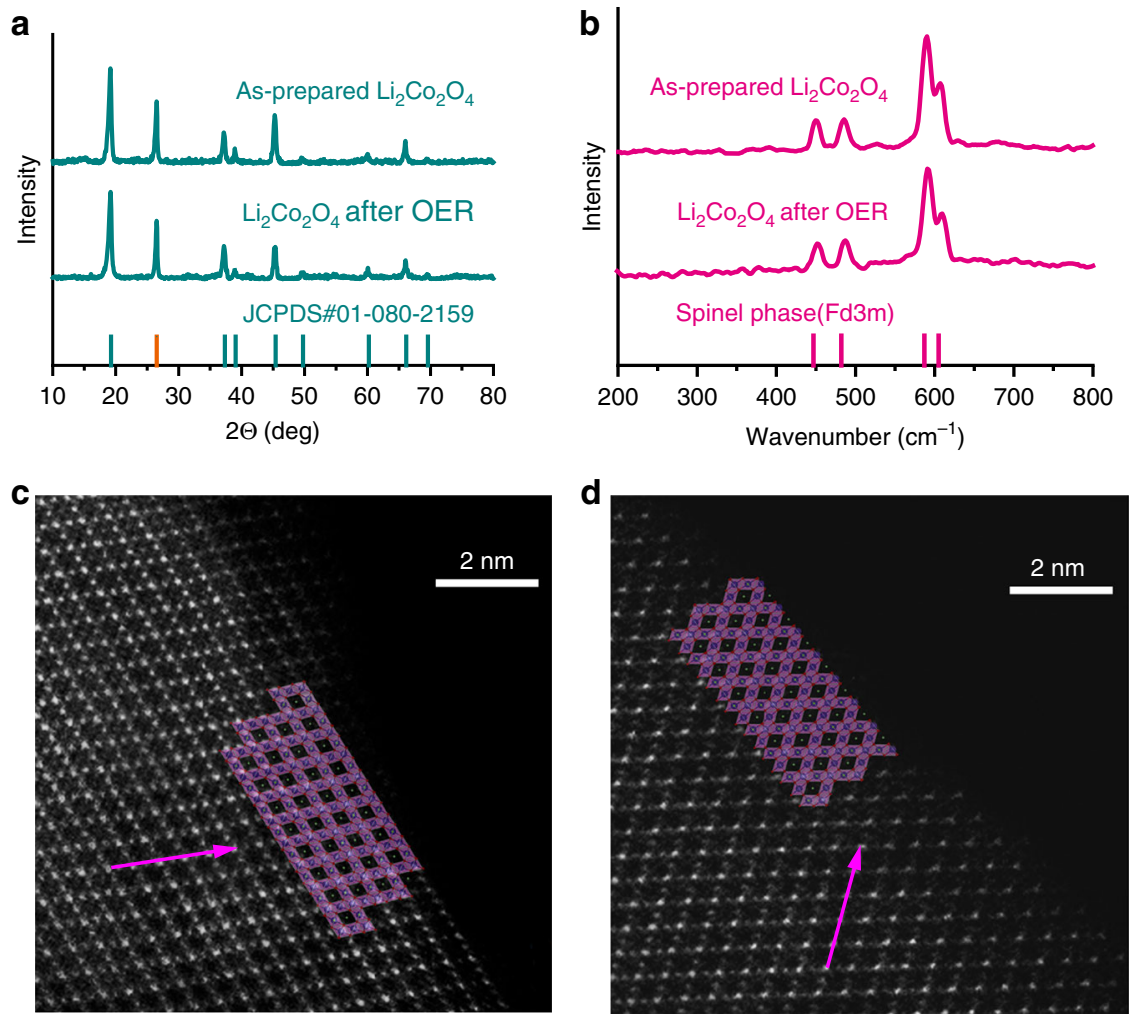

Fig. 4 Structural characterizations of $\mathrm{Li}_{\mathbf{2}} \mathrm{Co}_{\mathbf{2}} \mathbf{O}_{\mathbf{4}}$. a XRD patterns of $\mathrm{Li}_{2} \mathrm{Co}_{2} \mathrm{O}_{4}$ as prepared and after OER. The orange line corresponds to the XRD peak of the carbon fiber paper. $\mathbf{b}$ Raman spectra of $\mathrm{Li}_{2} \mathrm{CO}_{2} \mathrm{O}_{4}$ as prepared and after OER. $\mathbf{c}$ HAADF-STEM images of as-prepared $\mathrm{Li}_{2} \mathrm{Co}_{2} \mathrm{O}_{4}$. $\mathbf{d} \mathrm{HAADF}-\mathrm{STEM}$ images of $\mathrm{Li}_{2} \mathrm{CO}_{2} \mathrm{O}_{4}$ after OER. Both are viewed down the [110] zone axis, and the arrows are along the [1-11] direction.

$\mathrm{Li}_{2} \mathrm{Co}_{2} \mathrm{O}_{4}$ and $\mathrm{Li}_{1} \mathrm{Co}_{2} \mathrm{O}_{4}$ obtained from the three abovementioned OER mechanisms. The black lines and the magenta lines represent the $\mathrm{Co}^{3+}$ site and $\mathrm{Co}^{4+}$ site, respectively in Fig. $5 \mathrm{~d}-\mathrm{i}$. For $\mathrm{Li}_{2} \mathrm{Co}_{2} \mathrm{O}_{4}$, the MAE route has the lowest overpotential $(\eta)$ of $0.72 \mathrm{~V}$ among the three scenarios. The rate-limiting step is the formation of ${ }^{*} \mathrm{O}$ in this scenario. The theoretical potentials for LOV and MLOV are 2.46 and $2.09 \mathrm{~V}$, respectively, which are much higher than that of MAE. The rate-limiting steps of both cases are related to the formation of oxygen vacancies. Thus, we can conclude that the stable lattice oxygen for $\mathrm{Co}^{3+}$ oxide limits the formation of oxygen vacancies and that the contribution of the lattice-oxygen redox reaction to OER activity is less important for as-prepared $\mathrm{Co}^{3+} \mathrm{Li}_{2} \mathrm{Co}_{2} \mathrm{O}_{4}$; therefore, the OER activity mainly originates from the MAE route for the $\mathrm{Co}^{3+}$ state in the lattice.

In fact, during the OER process, part of the $\mathrm{Co}^{3+}$ ions are changed to $\mathrm{Co}^{4+}$ ions accompanied by delithiation, as found above. We turn to the delithiation $\mathrm{Li}_{1} \mathrm{Co}_{2} \mathrm{O}_{4}$. The negative chargetransfer energy of $\mathrm{Co}^{4+}$ ions in Co oxides leads to the appearance of unstable $\mathrm{O} 2 p$ holes $^{39}$ and favors the formation of oxygen vacancies. The calculated overpotential for $\mathrm{Li}_{1} \mathrm{Co}_{2} \mathrm{O}_{4}$ in the MLOV case is $0.46 \mathrm{~V}$, lower than the values of $0.98 \mathrm{~V}$ in the MAE scenario and $1.46 \mathrm{~V}$ in the LOV scenario, as shown in Fig. $5 \mathrm{~g}-\mathrm{i}$. In the MLOV route, the Gibbs free-energy difference $(\Delta G)$ of step 1 related to the formation of oxygen vacancies is much lower for $\mathrm{Li}_{1} \mathrm{Co}_{2} \mathrm{O}_{4}$ than for $\mathrm{Li}_{2} \mathrm{Co}_{2} \mathrm{O}_{4}$; thus, the rate-limiting step is changed to the adsorption of ${ }^{*} \mathrm{OH}$ in MLOV.

For $\mathrm{Li}_{1} \mathrm{Co}_{2} \mathrm{O}_{4}$, the $\Delta \mathrm{G}$ of step 1 for $\mathrm{Co}^{4+}$ is $\sim 0.3 \mathrm{eV}$ lower than that for $\mathrm{Co}^{3+}$ in the MLOV route, indicating again that the lattice oxygen around $\mathrm{Co}^{4+}$ is very unstable and is easily removed from the lattice, forming ${ }^{*} \mathrm{OO}$ intermediates. The different ratelimiting steps between $\mathrm{Co}^{3+}$ and $\mathrm{Co}^{4+}$ also originate from the different binding energies of $* \mathrm{OH}$. It is worth noting that although both the LOV and MLOV scenarios have considered the effects of the oxygen vacancy, the calculated total overpotential for $\mathrm{LOV}$ in $\mathrm{Li}_{1} \mathrm{Co}_{2} \mathrm{O}_{4}$ is much higher than that for MLOV, indicating the important role of the metal $\mathrm{Co}^{4+}$ site in the OER activity. If we replace distinguishable $\mathrm{Co}^{3+}$ and $\mathrm{Co}^{4+}$ with an average Co valence state, the LOV scenario is more favorable than the MAE route, as found previously ${ }^{14}$. The occurrence of highvalent $\mathrm{Co}^{4+}$ ions in the Co oxide leads to an increase in the $\mathrm{O} 2 p$ band center, whose positive effects on the OER activity were well studied previously ${ }^{14,40}$.

\section{Discussion}

The OER activity of $\mathrm{Li}_{2} \mathrm{Co}_{2} \mathrm{O}_{4}$ and many other Co oxide systems was attributed to the presence of Co ions which have their $e_{g}$ shell occupied by an electron ${ }^{41}$. Starting with an $\mathrm{LS} \mathrm{Co}^{3+}$ state in the as-prepared material, it was proposed that the $e_{g}$ shell acquires an electron by considering the formation of a $\mathrm{CoO}_{5}$ pyramidal coordination due to the loss of oxygen at the sample surface. We found no evidence for this in our experiments. First, we would like to point out that a loss of oxygen should decrease the valence of the Co ions; i.e., part of the $\mathrm{Co}^{3+}$ should be converted into $\mathrm{Co}^{2+}$. However, our Co- $\mathrm{L}_{2,3}$ spectra of the $\mathrm{Li}_{2} \mathrm{Co}_{2} \mathrm{O}_{4}$ catalyst material before and after the OER do not show features that otherwise could have indicated the presence of $\mathrm{Co}^{2+}$ species. As shown in Supplementary Fig. $4 \mathrm{f}, \mathrm{Co}^{2+}$ ion would have a sharp peak at $777.8 \mathrm{eV}$, which is totally absent in our $\mathrm{Li}_{2} \mathrm{Co}_{2} \mathrm{O}_{4}$ spectra both before and after the OER. In addition, our DFT calculations indicate that oxygen vacancies under OER conditions are very unstable and that they quickly become filled by $\mathrm{OH}$. Second, if the Co ion remains in the trivalent state when the $\mathrm{CoO}_{5}$ pyramidal coordination is formed, then there will be not one electron transferred to the $e_{g}$ shell but two electrons. The associated high- 

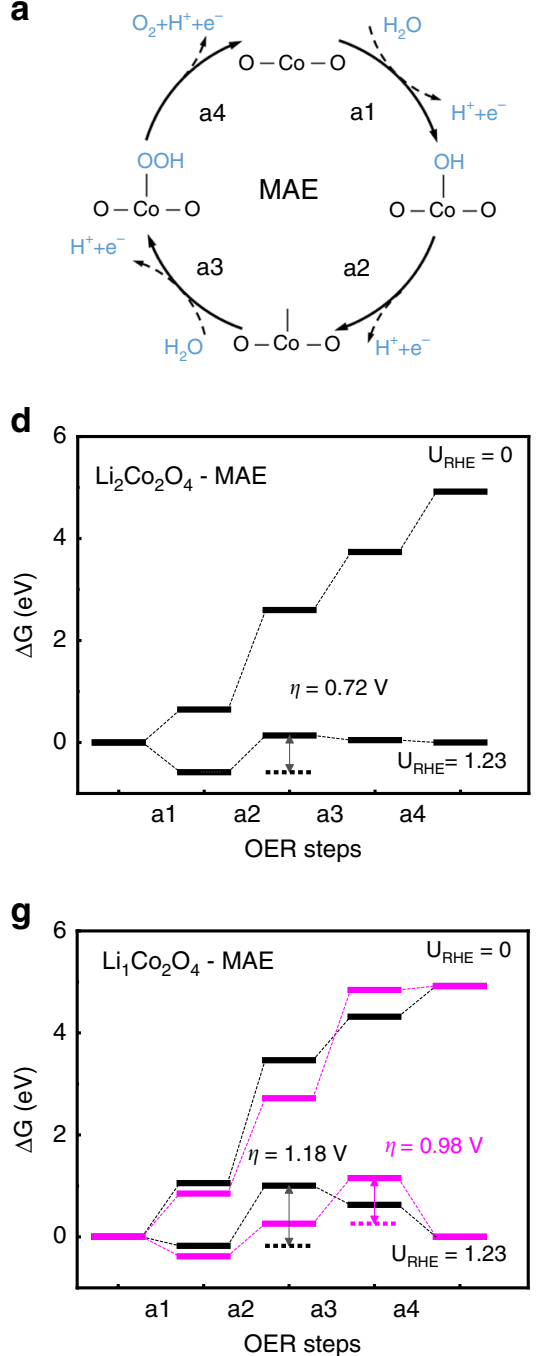

b
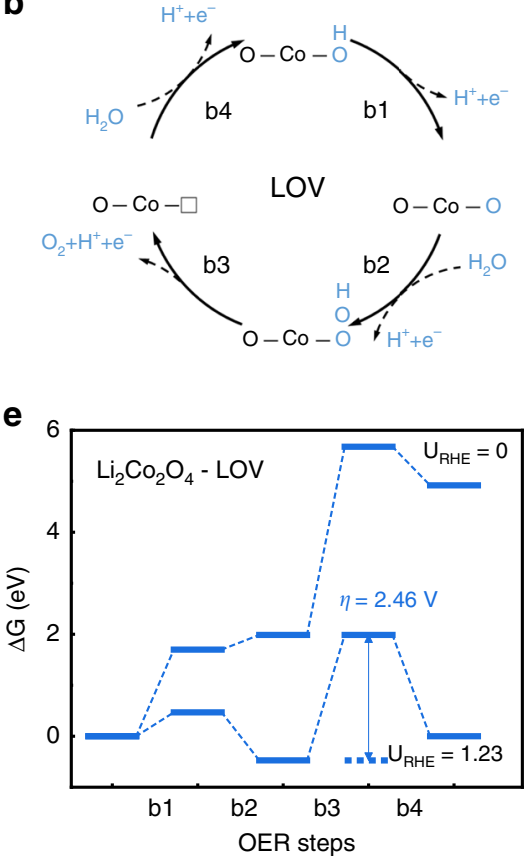

h

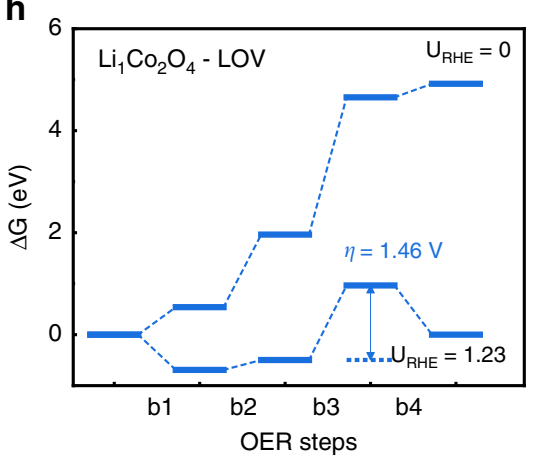

C

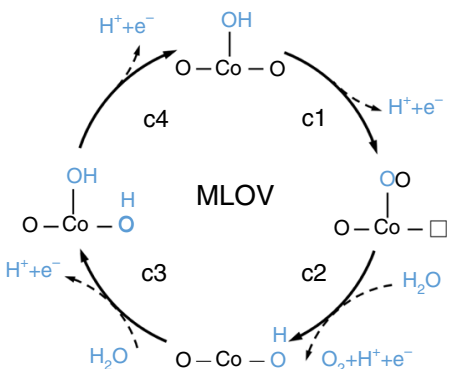

f

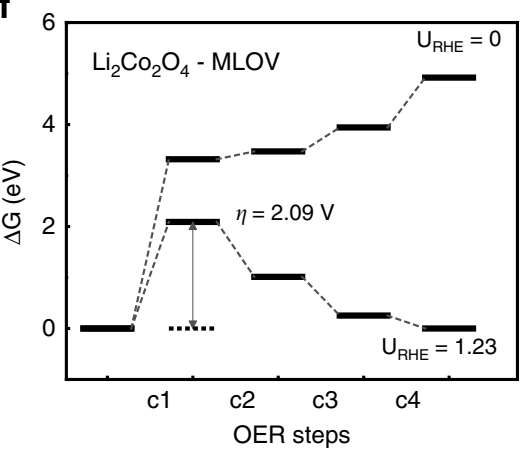

i

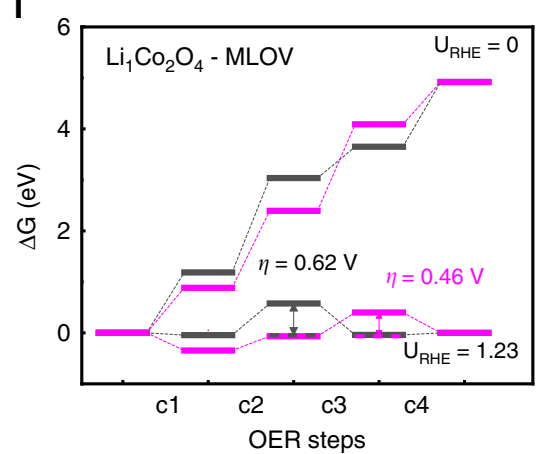

Fig. 5 Schematic OER mechanisms involving four concerted proton-electron transfer steps. a, $\mathbf{d}, \mathbf{g}$ MAE: this is a conventional OER mechanism, in which adsorbates are located at the transition-metal site. $\mathbf{b}, \mathbf{e}, \mathbf{h}$ LOV: in this scenario, adsorbates are only located at the site of the lattice-oxygen vacancy generated during redox reactions. c, f, i MLOV: in this scenario, adsorbates are located at both the transition-metal site and the oxygen vacancy site. The free energies under different potentials $U_{\mathrm{RHE}}$ for the OER on $\mathrm{Li}_{2} \mathrm{Co}_{2} \mathrm{O}_{4}$ in $\mathbf{d}-\mathbf{f}$ and $\mathrm{Li}_{1} \mathrm{Co}_{2} \mathrm{O}_{4}$ in $\mathbf{g}$-i. The black lines and the magenta lines indicate the $\mathrm{Co}^{3+}$ site and $\mathrm{Co}^{4+}$ site, respectively.

spin (HS) state for the $t_{2 g}{ }^{4} e_{g}^{2}$ configuration is well documented in the literature for $\mathrm{Co}^{3+}$ ions with pyramidal local coordination $^{42-46}$. The spectrum of such an $\mathrm{HS} \mathrm{CoO}_{5}$ pyramidal system is given in Supplementary Fig. $4 \mathrm{~d}$ and is very different from our $\mathrm{Li}_{2} \mathrm{Co}_{2} \mathrm{O}_{4}$ spectra. We thus can rule out the presence of $e_{g}$ electrons in our catalyst material before and after the OER.

Our in operando and in vacuo SXAS spectra instead showed a pure LS $\mathrm{Co}^{3+}$ state in $\mathrm{Li}_{2} \mathrm{Co}_{2} \mathrm{O}_{4}$ before the OER and that it is converted to an LS $\mathrm{Co}^{3.4+}$ state after the OER. This is also reconfirmed by comparing the spectra to those of known Co compounds in the literature. Supplementary Fig. $4 \mathrm{c}$ shows that the spectrum of $\mathrm{LiCoO}_{2}$, which is an $\mathrm{LS} \mathrm{Co}^{3+}$ system, is identical to that of the as-prepared $\mathrm{Li}_{2} \mathrm{Co}_{2} \mathrm{O}_{4}$. Supplementary Fig. 4 b displays that the spectrum of $\mathrm{Li}_{0.66} \mathrm{CoO}_{2}$, which is an LS $\mathrm{Co}^{3.34+}$ material, is very similar to that of $\mathrm{Li}_{2} \mathrm{Co}_{2} \mathrm{O}_{4}$ after the OER.

Our DFT calculations indicate that the $\mathrm{Co}^{4+}$ site spontaneously created under OER conditions is mainly responsible for the high OER activity. It is well known that the O $2 p$ to Co $3 d$ charge-transfer energy $\Delta$ (defined as the energy difference between the center $\mathrm{O} 2 p$ band and the upper-Hubbard band
(UHB), as shown in Supplementary Fig. 11) decreases with increasing valence state of the $\mathrm{TM}$ ion ${ }^{47}$. For $\mathrm{Co}^{2+}$, it is positive ${ }^{48,49}$; for $\mathrm{Co}^{3+}$, it is close to zero ${ }^{50}$; and for $\mathrm{Co}^{4+}$, it can be negative $27,28,51$. Consequently, the covalency increases, i.e., from rather ionic for $\mathrm{Co}^{2+}$, to highly covalent for $\mathrm{Co}^{3+}$, and further to $\mathrm{Co}^{4+}$, in which the holes mainly reside on the oxygen ligands rather than on the $\mathrm{Co}^{27,28}$. This trend can experimentally be directly observed in the O-K SXAS spectra: Supplementary Fig. 6 shows the spectral changes upon converting $\mathrm{CoO}$ to the asprepared $\mathrm{Li}_{2} \mathrm{Co}_{2} \mathrm{O}_{4}, \mathrm{Li}_{\mathrm{x}} \mathrm{CoO}_{2}$, and $\mathrm{Li}_{2} \mathrm{Co}_{2} \mathrm{O}_{4}$ after the OER and finally to $\mathrm{BaCoO}_{3}$. The figure displays how the spectral weight is shifting quickly to lower energies with increasing valence. The schematic density of states of $\mathrm{Co}^{3+}$ and $\mathrm{Co}^{4+}$ oxides (in the limit of no metal-ligand hybridization) is also shown in Supplementary Fig. 11 for $\mathrm{Co}^{3+}$ and $\mathrm{Co}^{4+}$ oxides. The relation between the charge-transfer energies $\Delta_{4+}$ and $\Delta_{3+}$ is $\Delta_{4+}=\Delta_{3+}-U+\delta$, where $U$ is the on-site Co $3 d$ Coulomb repulsion and $\delta$ is an extra gain originating from the lattice relaxation. It was previously found that the shift of the valence band center toward $E_{f}$ upon converting $\mathrm{Co}^{2+} / \mathrm{Co}^{3+}$ to the mixed $\mathrm{Co}^{3+} / \mathrm{Co}^{4+}$ oxide can easily facilitate the formation of $\mathrm{O}-\mathrm{O}^{5,13,40,52,53}$. 
Therefore, for $\mathrm{Co}^{4+}$ oxides, we have high unoccupied density states with $\mathrm{O} 2 p$ ligand character close to the chemical potential in the ground state ${ }^{28}$, which is generally denoted as the ligand oxygen hole $(\mathrm{LOH})^{27,28}$. Thus, the high OER activity of the electrochemical catalysts is intimately linked to the presence of large numbers of LOHs.

Nevertheless, one must also realize that an increase in the numbers of LOHs will make gradually the material unstable ${ }^{54}$. It is well known that $\mathrm{Co}^{4+}$ oxides such as $\mathrm{SrCoO}_{3}$ and $\mathrm{Sr}_{2} \mathrm{CoO}_{4}$ can easily decompose or become off-stoichiometric, even in air; in particular, $x$ cannot be reduced to zero for the $\mathrm{Li}_{x} \mathrm{CoO}_{2}$ and $\mathrm{Na}_{x} \mathrm{CoO}_{2}$ systems. We therefore suggest that perhaps a valence state of the Co ion in the range of $+3.3-+3.4$ would be a good starting point to find Co oxide materials that are highly OER active and yet also structurally stable. $\mathrm{La}_{0.6} \mathrm{Sr}_{0.4} \mathrm{Co}_{0.2} \mathrm{Fe}_{0.8} \mathrm{O}_{2.9}$ (Ref. ${ }^{55}$ ), $\mathrm{SrCoO}_{2.7}$ (Ref. ${ }^{15}$ ), $\mathrm{Pr}_{0.5} \mathrm{Ba}_{0.5} \mathrm{CoO}_{3-\delta}$ (Ref. ${ }^{40}$ ), $\mathrm{ZnFe}_{0.4^{-}}$ $\mathrm{Co}_{1.6} \mathrm{O}_{4}$ (Ref. ${ }^{34}$ ), and $\mathrm{Ba}_{4} \mathrm{Sr}_{4}\left(\mathrm{Co}_{0.8} \mathrm{Fe}_{0.2}\right)_{4} \mathrm{O}_{15}$ (Ref. ${ }^{56}$ ) may serve as examples, together with $\mathrm{LiCoO}_{2}$ (Ref. ${ }^{38}$ ) and $\mathrm{Li}_{2} \mathrm{Co}_{2} \mathrm{O}_{4}$, which are delithiated under OER conditions.

In summary, the origin of the high OER activity of the $\mathrm{Li}_{2} \mathrm{Co}_{2} \mathrm{O}_{4}$ catalyst was revealed by our in operando SXAS measurements as a function of applied voltage and time. We have observed that an irreversible valence-state transition from $\mathrm{Co}^{3+}$ to $\mathrm{Co}^{3.4+}$ occurs under OER conditions. This transition is accompanied by a delithiation process. The low-spin state of the Co ions, however, remains unchanged. No complete change from the edge-shared network to the corner-shared network can be observed. The underlying mechanism of the OER activity was then revealed by DFT calculations, which indicated that the adsorbates located at the $\mathrm{Co}^{4+}$ sites have a lower overall overpotential for the OER process than those located at the $\mathrm{Co}^{3+}$ sites or oxygen vacancy sites. The microscopic origin is the dominant O $2 p$ hole characteristic of the ground state of $\mathrm{Co}^{4+}$ having a negative charge-transfer energy. In such cases, the $\mathrm{O} 2 p$ hole is due to the strong Co $3 d-\mathrm{O} 2 p$ covalence, which is different from the strong $\mathrm{O} 2 p-\mathrm{O} 2 p$ bond occurring in peroxo-like $\left(\mathrm{O}_{2}\right)^{n-}$ species. We suggest that the ideal valence state of the Co ions for high OER activity is $\mathrm{Co}^{3.3+}-\mathrm{Co}^{3.4+}$. This can be either prepared or spontaneously created under OER conditions. A higher content of $\mathrm{Co}^{4+}$ may increase the activity but will also lead to a decrease in the structural stability of the catalyst material.

\section{Methods}

Synthesis. To obtain a very small average size of the particles that is suitable for in operando soft X-ray absorption experiments, $\mathrm{Li}_{2} \mathrm{Co}_{2} \mathrm{O}_{4}$ was prepared by the citrate sol-gel method as follows: lithium acetate $(\geq 99.9 \%$, Alfa Aesar), cobalt acetate hexahydrate ( $\geq 99.9 \%$, Alfa Aesar), citrate ( $\geq 99.5 \%$, Aladdin), and urea ( $\geq 99 \%$, Aladdin) were dissolved in distilled water with a mole ratio of 1:1:2:2. The solution was evaporated at $80^{\circ} \mathrm{C}$ with magnetic stirring for $4 \mathrm{~h}$ and then transferred to an oven at $180^{\circ} \mathrm{C}$ overnight to obtain a gel. Afterwards, the gel was calcined at $350{ }^{\circ} \mathrm{C}$ for $48 \mathrm{~h}$ to obtain $\mathrm{Li}_{2} \mathrm{Co}_{2} \mathrm{O}_{4}$

Physicochemical characterization. The structure and phases of $\mathrm{Li}_{2} \mathrm{Co}_{2} \mathrm{O}_{4}$ before and after the OER were identified using grazing incidence X-ray diffraction (XRD, Bruker D8-Advance AXS diffractometer with $\mathrm{Cu} \mathrm{K}_{\alpha}$ irradiation and an incidence angle of $1^{\circ}$ ) and Raman (Horiba XploRA confocal Raman Microscope with laser wavelength of $532 \mathrm{~nm}$ ). It is worth noting that the laser power for the Raman experiment was only $0.2 \mathrm{~mW}$ to avoid a structure phase transition caused by the laser. The morphology of the samples was characterized by transmission electron microscopy (TEM, FEI Tecnai G2 F20 S-TWIN) and scanning transmission electron microscopy (STEM, FEI aberration corrected Titan G2 60-300 with convergence angle of $\sim 21.4 \mathrm{mrad}$ and camera length of $\sim 145 \mathrm{~mm}$ ). The elemental compositions were measured by inductively coupled plasma-optical emission spectrometry (Spectro Arcos SOP).

Electrochemical measurements at home institute. Electrochemical measure ments were conducted using an electrochemical workstation (Metrohm Autolab PGSTAT $302 \mathrm{~N}$ ) with a standard three-electrode electrochemical cell. The catalysts loaded on carbon paper with a loading mass of $0.3 \mathrm{mg} \mathrm{cm}^{-2}$ via drop-casting, $\mathrm{Hg}$ / $\mathrm{HgO}(1 \mathrm{M} \mathrm{KOH})$ and Pt foil acted as the working, reference and counter electrodes, respectively. All electrochemical experiments were performed in freshly prepared $\mathrm{O}_{2}$-saturated $\mathrm{KOH}$ ( $\mathrm{pH}=12.5-14 ; 99.99 \%$, Alfa Aesar). Polarization curves for $\mathrm{Li}_{2} \mathrm{Co}_{2} \mathrm{O}_{4}$ were recorded at a scan rate of $10 \mathrm{mV} \mathrm{s}^{-1}$, and cyclic voltammograms were recorded at a scan rate of $5 \mathrm{mV} \mathrm{s}^{-1}$. Unless specifically mentioned, all electrode potentials used in this study were referenced to the RHE and iR-corrected to compensate for the effect of solution resistance.

Soft X-ray absorption spectroscopy. The in operando SXAS experiments at the $\mathrm{O}-\mathrm{K}$ and $\mathrm{Co}-\mathrm{L}_{2,3}$ edges were carried out at the $11 \mathrm{~A}$ beam line of the National Synchrotron Radiation Research Center in Taiwan using the TFY mode. NiO and $\mathrm{CoO}$ single crystals purchased from Matek Material Technologie \& Kristalle GmbH were recorded simultaneously in a separate ultrahigh vacuum chamber in TEY mode to serve as relative energy calibration for the measurements at the $\mathrm{O}-\mathrm{K}$ and $\mathrm{Co}-\mathrm{L}_{2,3}$ edges, respectively. The SXAS spectra of the as-prepared $\mathrm{Li}_{2} \mathrm{Co}_{2} \mathrm{O}_{4}$ and $\mathrm{Li}_{2} \mathrm{Co}_{2} \mathrm{O}_{4}$ after the OER were measured using both TEY and TFY modes simultaneously. A correction for the self-absorption effects in the TFY spectra was applied $^{57,58}$. There are several reasons why we performed the operando timedependent TFY SXAS only at the O-K edge. First, in the conversion from $\mathrm{Co}^{3+}$ to $\mathrm{Co}^{4+}$, the created holes mainly reside in the O $2 p$ states; therefore, the O-K SXAS spectrum is more sensitive to them than the Co- $\mathrm{L}_{2,3}$ SXAS. Second, the O-K SXAS spectrum for an edge-shared network presents separated the features for $\mathrm{Co}^{3+}$ and $\mathrm{Co}^{4+}$ as well as $t_{2 g^{-}}$and $e_{g}$-related holes well, while the increase in Co valence mainly produced a slight energy shift in the TFY Co- $\mathrm{L}_{2,3}$ SXAS. Finally, in terms of practicality, each Co- $\mathrm{L}_{2,3}$ spectrum with reasonable statistics took more than $20 \mathrm{~min}$, which is too slow to detect the time-dependent effects for the operando experiments.

For SXAS measurements, the $\mathrm{Li}_{2} \mathrm{Co}_{2} \mathrm{O}_{4}$ catalyst powder was dispersed in ethanol and deionized water and then sonicated for $30 \mathrm{~min}$. The ink was then dropcast on carbon paper with a loading mass of $0.3 \mathrm{mg} \mathrm{cm}^{-2}$ for ex situ SXAS experiments. For in operando experiments, the ink was dropped into the thin membrane window $\left(100 \mathrm{~nm}\right.$ silicon nitride with a $1 \times 1 \mathrm{~mm}^{2}$ area coated by $3 \mathrm{~nm}$ $\mathrm{Ti} / 10 \mathrm{~nm} \mathrm{Au}$ from Silson Ltd) with a loading mass of $\sim 1 \mathrm{mg} \mathrm{cm}^{-2}$. This window was used as the working electrode and to separate the liquid and the ultrahigh vacuum environment. The in operando SXAS experiments were performed using an in situ electrochemical liquid cell ${ }^{59,60}$ equipped with three electrodes (working, reference, and counter electrodes) under control by a VersaSTAT 3 potentiostat from Princeton Applied Research. Two platinum wires were used as the reference and counter electrodes. Here, we selected a Pt pseudoreference electrode due to space constrictions in the electrochemical cell and calibrated the potential to RHE following the procedure described by Kasem and Jones ${ }^{61}$. Freshly prepared $\mathrm{O}_{2}-$ saturated $1.0 \mathrm{M} \mathrm{KOH}$ was used as the electrolyte, and the electrochemical liquid cell system also contained a liquid pump, an inlet, and an outlet tube for the electrolyte flow.

TFY was used as the detection method for the absorption signal in the in operando SXAS experiments. A photon escape depth of $\sim 200 \mathrm{~nm}$ is sufficiently large to overcome the liquid region and the membrane separating the liquid from the ultrahigh vacuum. The particle size and distribution of $\mathrm{Li}_{2} \mathrm{Co}_{2} \mathrm{O}_{4}$ nanoparticles used for the SXAS experiments were determined by high-resolution transmission electron microscopy in Supplementary Fig. 8. The average size of particles was $<20 \mathrm{~nm}$, which can ensure sensitivity to the surface region of the catalyst material for SXAS measurements. Assuming that the active region for the OER reaction is within a depth of $\sim 5 \mathrm{~nm}$ from the surface ${ }^{14,62}$, it can be estimated that $\sim 80 \%$ of the TFY signal originates from this region. This is illustrated in Supplementary Fig. 9, which shows how the ratio of the surface-to-bulk contribution in the TFY gradually increases as the size of particles decreases.

Density function theory calculations. All DFT calculations were performed with the Vienna Ab initio Simulation Package ${ }^{63,64}$ using projector-augmented wave pseudopotentials and the Perdew-Burke-Ernzenhof ${ }^{65}$ exchange correlation functional. The energy cutoff of the plane wave was $500 \mathrm{eV}$. To describe the strong correlation of the localized Co $3 d$ states, the Hubbard $U$ model ${ }^{66}$ was applied, and the value of $U_{\text {eff }}(=U-J)$ was set to $3.52 \mathrm{eV}$ according to previous work ${ }^{12}$. The experimental lattice constants were adopted, and the geometries were relaxed until a maximum threshold force of $0.02 \mathrm{eV} / \AA$ was fulfilled. For computational efficiency, a $3 \times 3 \times 1$ Monkhorst-Pack k-point mesh was used for all calculations. The systems were initiated with Co atoms in a ferromagnetic configuration, which was allowed to evolve during the calculations. A $1 \times 1$ primitive cell (lattice constants are $7.9825 \AA$ ) was employed to build periodic slab models, with four Co sites per surface. There were eight atomic layers in the slab models, and four layers at the bottom were fixed during the relaxation. The thickness of vacuum spacing perpendicular to the surface was $\sim 20 \AA$ to prevent spurious interactions.

The overpotentials for $\mathrm{Li}_{2} \mathrm{Co}_{2} \mathrm{O}_{4}$ surfaces were calculated considering three scenarios of the reaction mechanism ${ }^{12,14,15}$. Elementary steps and all the corresponding equations considered for three scenarios of the reaction mechanism are provided in the supplementary information. The Gibbs free-energy differences were calculated using the computational hydrogen electrode model under standard conditions $^{12}$. We considered voltage applied $U_{\mathrm{RHE}}=0$ and $1.23 \mathrm{~V}$. The zero-point energy (ZPE) and entropy corrections were calculated according to the literature $^{12,15}$ (Supplementary Table 2). The experimental Gibbs free formation energies and entropic contributions of $\mathrm{H}_{2} \mathrm{O}$ and $\mathrm{H}_{2}$ under standard conditions 
( $T=298 \mathrm{~K}$ and $P=1 \mathrm{bar}$ ) were obtained from the CRC Hanbook ${ }^{67}$. For the adsorbed species, the ZPEs were calculated for the (001) $\mathrm{Li}_{2} \mathrm{Co}_{2} \mathrm{O}_{4}$ surface. The entropy corrections for the adsorbent on the surface were considered zero, since the main contribution to the entropy is due to the translational entropy. The theoretical overpotential $(\eta)$ was defined from the Gibbs free-energy differences at each step.

$$
\eta=\max \left[\Delta G_{i}\right] / e-1.23 \mathrm{~V}
$$

\section{Data availability}

The data that support the findings of this study are available from the corresponding authors upon request. The source data underlying Figs. 1-3, 4a, b, 5d-i and Supplementary Figs. 1-7, 8b, and 9 are provided as a Source Data file.

Received: 19 November 2019; Accepted: 1 April 2020;

Published online: 24 April 2020

\section{References}

1. Chen, D., Chen, C., Baiyee, Z. M., Shao, Z. \& Ciucci, F. Nonstoichiometric oxides as low-cost and highly-efficient oxygen reduction/evolution catalysts for low-temperature electrochemical devices. Chem. Rev. 115, 9869-9921 (2015).

2. Song, F. et al. Transition metal oxides as electrocatalysts for the oxygen evolution reaction in alkaline solutions: an application-inspired renaissance. J. Am. Chem. Soc. 140, 7748-7759 (2018).

3. Wang, H.-Y. et al. In operando identification of geometrical-sitedependent water oxidation activity of spinel $\mathrm{Co}_{3} \mathrm{O}_{4}$. J. Am. Chem. Soc. 138 , 36-39 (2016)

4. Bergmann, A. et al. Unified structural motifs of the catalytically active state of $\mathrm{Co}$ (oxyhydr)oxides during the electrochemical oxygen evolution reaction. Nat. Catal. 1, 711-719 (2018).

5. Hwang, J. et al. Perovskites in catalysis and electrocatalysis. Science 358, 751-756 (2017).

6. Suntivich, J., May, K. J., Gasteiger, H. A., Goodenough, J. B. \& Shao-Horn, Y. A perovskite oxide optimized for oxygen evolution catalysis from molecular orbital principles. Science 334, 1383-1385 (2011).

7. Fominykh, K. et al. Rock salt Ni/Co oxides with unusual nanoscale-stabilized composition as water splitting electrocatalysts. Adv. Funct. Mater. 27, 1605121 (2017).

8. Zhang, B. et al. Homogeneously dispersed multimetal oxygen-evolving catalysts. Science 352, 333-337 (2016).

9. Huang, Z.-F. et al. Chemical and structural origin of lattice oxygen oxidation in Co-Zn oxyhydroxide oxygen evolution electrocatalysts. Nat. Energy $\mathbf{4}$, 329-338 (2019).

10. Friebel, D. et al. Identification of highly active $\mathrm{Fe}$ sites in $(\mathrm{Ni}, \mathrm{Fe}) \mathrm{OOH}$ for electrocatalytic water splitting. J. Am. Chem. Soc. 137, 1305-1313 (2015).

11. Goerlin, M. et al. Tracking catalyst redox states and reaction dynamics in $\mathrm{Ni}-\mathrm{Fe}$ oxyhydroxide oxygen evolution reaction electrocatalysts: the role of catalyst support and electrolyte pH. J. Am. Chem. Soc. 139, 2070-2082 (2017).

12. Bajdich, M., Garcia-Mota, M., Vojvodic, A., Norskov, J. K. \& Bell, A. T. Theoretical investigation of the activity of cobalt oxides for the electrochemical oxidation of water. J. Am. Chem. Soc. 135, 13521-13530 (2013)

13. Hong, W. T. et al. Charge-transfer-energy-dependent oxygen evolution reaction mechanisms for perovskite oxides. Energy Environ. Sci. 10, 2190-2200 (2017).

14. Grimaud, A. et al. Activating lattice oxygen redox reactions in metal oxides to catalyse oxygen evolution. Nat. Chem. 9, 457 (2017).

15. Mefford, J. T. et al. Water electrolysis on $\mathrm{La}_{1-\mathrm{x}} \mathrm{Sr}_{\mathrm{x}} \mathrm{CoO}_{3-\delta}$ perovskite electrocatalysts. Nat. Commun. 7, 11053 (2016).

16. Seh, Z. W. et al. Combining theory and experiment in electrocatalysis: Insights into materials design. Science 355, eaad4998 (2017).

17. Risch, M. et al. Structural changes of cobalt-based perovskites upon water oxidation investigated by EXAFS. J. Phys. Chem. C. 117, 8628-8635 (2013).

18. May, K. J. et al. Influence of oxygen evolution during water oxidation on the surface of perovskite oxide catalysts. J. Phys. Chem. Lett. 3, 3264-3270 (2012).

19. Song, S. et al. Understanding the origin of high oxygen evolution reaction activity in the high Sr-doped perovskite. Chin. J. Catal. 41, 592-597 (2020).

20. Fabbri, E. et al. Dynamic surface self-reconstruction is the key of highly active perovskite nano-electrocatalysts for water splitting. Nat. Mater. 16, 925-931 (2017).

21. $\mathrm{Lu}, \mathrm{N}$. et al. Electric-field control of tri-state phase transformation with a selective dual-ion switch. Nature 546, 124 (2017).

22. Le Toquin, R., Paulus, W., Cousson, A., Prestipino, C. \& Lamberti, C. Timeresolved in situ studies of oxygen intercalation into $\mathrm{SrCoO}_{2.5}$, performed by neutron diffraction and X-ray absorption spectroscopy. J. Am. Chem. Soc. 128, 13161-13174 (2016)

23. Zhang, M., de Respinis, M. \& Frei, H. Time-resolved observations of water oxidation intermediates on a cobalt oxide nanoparticle catalyst. Nat. Chem. 6 , 362-367 (2014).

24. Herlihy, D. M. et al. Detecting the oxyl radical of photocatalytic water oxidation at an $\mathrm{n}-\mathrm{SrTiO}_{3} /$ aqueous interface through its subsurface vibration. Nat. Chem. 8, 549-555 (2016).

25. Zandi, O. \& Hamann, T. W. Determination of photoelectrochemical water oxidation intermediates on haematite electrode surfaces using operando infrared spectroscopy. Nat. Chem. 8, 778-783 (2016).

26. Chen, X., Aschaffenburg, D. J. \& Cuk, T. Selecting between two transition states by which water oxidation intermediates decay on an oxide surface. Nat. Catal. 2, 820-827 (2019).

27. Chin, Y. Y. et al. Spin-orbit coupling and crystal-field distortions for a lowspin $3 \mathrm{~d}^{5}$ state in $\mathrm{BaCoO}_{3}$. Phys. Rev. B 100, 205139 (2019).

28. Potze, R. H., Sawatzky, G. A. \& Abbate, M. Possibility for an intermediate-spin ground state in the charge-transfer material $\mathrm{SrCoO}_{3}$. Phys. Rev. B 51, 11501-11506 (1995).

29. Mizokawa, T. et al. Role of oxygen holes in $\mathrm{LiCoO}_{2}$ revealed by soft X-ray spectroscopy. Phys. Rev. Lett. 111, 056404 (2013).

30. $\mathrm{Wu}, \mathrm{W}$. B. et al. Orbital symmetry and electron correlation in $\mathrm{Na}_{\mathrm{x}} \mathrm{CoO}_{2}$. Phys. Rev. Lett. 94, 146402 (2005)

31. Maiyalagan, T., Jarvis, K. A., Therese, S., Ferreira, P. J. \& Manthiram, A. Spinel-type lithium cobalt oxide as a bifunctional electrocatalyst for the oxygen evolution and oxygen reduction reactions. Nat. Commun. 5, 3949 (2014).

32. Trzesniewski, B. J. et al. In situ observation of active oxygen species in Fecontaining Ni-based oxygen evolution catalysts: The effect of $\mathrm{pH}$ on electrochemical activity. J. Am. Chem. Soc. 137, 15112-15121 (2015).

33. Yang, C. et al. Revealing $\mathrm{pH}$-dependent activities and surface instabilities for Ni-based electrocatalysts during the oxygen evolution reaction. ACS Energy Lett. 3, 2884-2890 (2018).

34. Zhou, Y. et al. Enlarged Co-O covalency in octahedral sites leading to highly efficient spinel oxides for oxygen evolution reaction. Adv. Mater. 30, 1802912 (2018).

35. Kurata, H., Lefèvre, E., Colliex, C. \& Brydson, R. Electron-energy-loss nearedge structures in the oxygen K-edge spectra of transition-metal oxides. Phys. Rev. B 47, 13763-13768 (1993).

36. Burnus, T. et al. Local electronic structure and magnetic properties of $\mathrm{LaMn}_{0.5} \mathrm{Co}_{0.5} \mathrm{O}_{3}$ studied by $\mathrm{x}$-ray absorption and magnetic circular dichroism spectroscopy. Phys. Rev. B 77, 125124 (2008).

37. Lin, H. J. et al. Local orbital occupation and energy levels of $\mathrm{Co}$ in $\mathrm{Na}_{\mathrm{x}} \mathrm{CoO}_{2}$ : a soft x-ray absorption study. Phys. Rev. B 81, 115138 (2010).

38. Colligan, N., Augustyn, V. \& Manthiram, A. Evidence of localized lithium removal in layered and lithiated spinel $\mathrm{Li}_{1-\mathrm{x}} \mathrm{CoO}_{2}(0 \leq \mathrm{x} \leq 0.9)$ under oxygen evolution reaction conditions. J. Phys. Chem. C 119, 2335-2340 (2015).

39. Liu, H. J. et al. Insight into the role of metal-oxygen bond and $\mathrm{O} 2 \mathrm{p}$ hole in high-voltage cathode $\mathrm{LiNi}_{\mathrm{x}} \mathrm{Mn}_{2-\mathrm{x}} \mathrm{O}_{4}$. J. Phys. Chem. C 121, 16079-16087 (2017).

40. Grimaud, A. et al. Double perovskites as a family of highly active catalysts for oxygen evolution in alkaline solution. Nat. Commun. 4, 2439 (2013).

41. Maitra, U., Naidu, B. S., Govindaraj, A. \& Rao, C. N. R. Importance of trivalency and the $\mathrm{e}_{\mathrm{g}}{ }^{1}$ configuration in the photocatalytci oxidation of water by $\mathrm{Mn}$ and Co oxides. Proc. Natl. Acad. Sci. U.S.A. 119, 11704-11707 (2013).

42. Chang, C. F. et al. Spin blockade, orbital occupation, and charge ordering in $\mathrm{La}_{1.5} \mathrm{Sr}_{0.5} \mathrm{CoO}_{4}$. Phys. Rev. Lett. 102, 116401 (2009).

43. Knee, C. S., Price, D. J., Lees, M. R. \& Weller, M. T. Two- and threedimensional magnetic order in the layered cobalt oxychloride $\mathrm{Sr}_{2} \mathrm{CoO}_{3} \mathrm{Cl}$. Phys. Rev. B 68, 174407 (2003).

44. Sudayama, T. et al. Co-O-O-Co superexchange pathways enhanced by small charge-transfer energy in multiferroic $\mathrm{BiCoO}_{3}$. Phys. Rev. B 83, 235105 (2011).

45. Oka, K. et al. Pressure-induced spin-state transition in $\mathrm{BiCoO}_{3}$. J. Am. Chem. Soc. 132, 9438-9443 (2010).

46. Chin, Y.-Y. et al. Experimental and theoretical soft X-ray absorption study on $\mathrm{Co}^{3+}$ ion spin states in $\mathrm{Sr}_{2-\mathrm{x}} \mathrm{Ca}_{\mathrm{x}} \mathrm{CoO}_{3}$ F. Phys. Status Solidi RRL 12, 1800147 (2018).

47. Bocquet, A. E., Mizokawa, T., Saitoh, T., Namatame, H. \& Fujimori, A. Electronic structure of $3 \mathrm{~d}$-transition-metal compounds by analysis of the $2 \mathrm{p}$ core-level photoemission spectra. Phys. Rev. B 46, 3771-3784 (1992).

48. Csiszar, S. I. et al. Controlling orbital moment and spin orientation in $\mathrm{CoO}$ layers by strain. Phys. Rev. Lett. 95, 187205 (2005).

49. van Elp, J. et al. Electronic structure of $\mathrm{CoO}$, Li-doped $\mathrm{CoO}$, and $\mathrm{LiCoO}_{2}$. Phys. Rev. B 44, 6090-6103 (1991).

50. Haverkort, M. W. et al. Spin state transition in $\mathrm{LaCoO}_{3}$ studied using soft Xray absorption spectroscopy and magnetic circular dichroism. Phys. Rev. Lett. 97, 176405 (2006). 
51. Abbate, $\mathrm{M}$. et al. X-ray absorption of the negative charge-transfer material $\mathrm{SrFe}_{1-\mathrm{x}} \mathrm{Co}_{\mathrm{x}} \mathrm{O}_{3}$. Phys. Rev. B 65, 165120 (2002).

52. $\mathrm{Wu}$, $\mathrm{T}$. et al. Iron-facilitated dynamic active-site generation on spinel $\mathrm{CoAl}_{2} \mathrm{O}_{4}$ with self-termination of surface reconstruction for water oxidation. Nat. Catal. 2, 763-772 (2019)

53. Bak, J., Bin Bae, H. \& Chung, S.-Y. Atomic-scale perturbation of oxygen octahedra via surface ion exchange in perovskite nickelates boosts water oxidation. Nat. Commun. 10, 2713 (2019).

54. Grimaud, A., Hong, W. T., Shao-Horn, Y. \& Tarascon, J. M. Anionic redox processes for electrochemical devices. Nat. Mater. 15, 121-126 (2016).

55. Song, $\mathrm{S}$. et al. Molten-salt synthesis of porous $\mathrm{La}_{0.6} \mathrm{Sr}_{0.4} \mathrm{Co}_{0.2} \mathrm{Fe}_{0.8} \mathrm{O}_{2.9}$ perovskite as an efficient electrocatalyst for oxygen evolution. Nano Res. 11, 4796-4805 (2018).

56. Zhu, Y. et al. Boosting oxygen evolution reaction by creating both metal ion and lattice-oxygen active sites in a complex oxide. Adv. Mater. 32, 1905025 (2020).

57. Itano, W. M. et al. Quantum projection noise: Population fluctuations in twolevel systems. Phys. Rev. A 47, 3554-3570 (1993).

58. Pellegrin, E. et al. Orbital character of states at the Fermi level in $\mathrm{La}_{2-\mathrm{x}} \mathrm{Sr}_{\mathrm{x}} \mathrm{CuO}_{4}$ and $\mathrm{R}_{2-\mathrm{x}} \mathrm{Ce}_{\mathrm{x}} \mathrm{CuO}_{4}(\mathrm{R}=\mathrm{Nd}, \mathrm{Sm})$. Phys. Rev. B 47, 3354-3367 (1993).

59. Guo, J. et al. Soft-x-ray spectroscopy experiment of liquids. J. Vac. Sci. Technol. A 25, 1231-1233 (2007).

60. Jiang, P. et al. In situ soft X-ray absorption spectroscopy investigation of electrochemical corrosion of copper in aqueous $\mathrm{NaHCO}_{3}$ solution. Electrochem. Commun. 12, 820-822 (2010).

61. Kasem, B. K. K. \& Jones, S. Platinum as a reference electrode in electrochemical measurements. Platin. Met. Rev. 52, 100-106 (2008).

62. Zhou, S. M. et al. Engineering electrocatalytic activity in nanosized perovskite cobaltite through surface spin-state transition. Nat. Commun. 7 , 11510 (2016)

63. Kresse, G. \& Furthmüller, J. Efficient iterative schemes for ab initio totalenergy calculations using a plane-wave basis set. Phys. Rev. B 54, 11169-11186 (1996).

64. Kresse, G. \& Joubert, D. From ultrasoft pseudopotentials to the projector augmented-wave method. Phys. Rev. B 59, 1758-1775 (1999).

65. Perdew, J. P., Burke, K. \& Ernzerhof, M. Generalized gradient approximation made simple. Phys. Rev. Lett. 77, 3865-3868 (1996).

66. Dudarev, S. L., Botton, G. A., Savrasov, S. Y., Humphreys, C. J. \& Sutton, A. P. Electron-energy-loss spectra and the structural stability of nickel oxide: an LSDA+U study. Phys. Rev. B 57, 1505-1509 (1998).

67. Jenkins, S. CRC Handbook of Chemistry and Physics 93rd ed., (CRC Press, Boca Raton, FL, 2012).

\section{Acknowledgements}

This work was supported by the "Transformational Technologies for Clean Energy and Demonstration," Strategic Priority Research Program of the Chinese Academy of Sciences (Grant No. XDA2100000), the K. C. Wong Education Foundation (Grant No.
GJTD-2018-10), Youth Innovation Promotion Association, Chinese Academy of Science (Grant No. 2014237), the National Science Foundation of China (Grant No. 21876183 and No. 21905295), and Instrument and Equipment Development Program Chinese Academy of Science (Grant No. YJKYYQ20180066). We acknowledge the support from the Max Planck-POSTECH-Hsinchu Center for Complex Phase Materials. We are also grateful to Piheng Chen and Rongguang Zeng for the STEM measurements.

\section{Author contributions}

Z.H. and L.Z. conceived the project and designed the experiments. J.Z. conducted material synthesis and performed electrochemical measurements. J.Z., Y.-C.H., C.-L.D., H.-J.L.

C.-T.C., and Z.H. performed the in operando SXAS experiments and data analysis. L.Z. and J.Z. performed structural characterization. J.Z. carried out DFT calculations. L.Z., Z H., and L.H.T. wrote the manuscript. Z.H. and L.H.T. provided interpretation of SXAS. All authors discussed the results and commented on the manuscript.

\section{Competing interests}

The authors declare no competing interests.

\section{Additional information}

Supplementary information is available for this paper at https://doi.org/10.1038/s41467 020-15925-2.

Correspondence and requests for materials should be addressed to L.Z. or Z.H.

Peer review information Nature Communications thanks Zhichuan Xu and other, anonymous, reviewers for their contributions to the peer review of this work.

Reprints and permission information is available at http://www.nature.com/reprints

Publisher's note Springer Nature remains neutral with regard to jurisdictional claims in published maps and institutional affiliations.

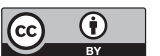

Open Access This article is licensed under a Creative Commons Attribution 4.0 International License, which permits use, sharing, adaptation, distribution and reproduction in any medium or format, as long as you give appropriate credit to the original author(s) and the source, provide a link to the Creative Commons license, and indicate if changes were made. The images or other third party material in this article are included in the article's Creative Commons license, unles indicated otherwise in a credit line to the material. If material is not included in the article's Creative Commons license and your intended use is not permitted by statutory regulation or exceeds the permitted use, you will need to obtain permission directly from the copyright holder. To view a copy of this license, visit http://creativecommons.org/ licenses/by/4.0/.

(C) The Author(s) 2020 